\title{
Acute respiratory distress syndrome secondary to High-altitude pulmonary edema: A diagnostic study
}

\author{
Si Qing Ma ${ }^{1}$, Tian $\mathrm{Yi} \mathrm{Wu}^{2,3 *}$ Qiang Cheng ${ }^{1}$, Pei $\mathrm{Li}^{1}$ and Hui Ping Bian ${ }^{4}$ \\ ${ }^{1}$ Intensive Care Unit, Qinghai Provincial People's Hospital, Xining, People's Republic of China. \\ ${ }^{2}$ National Key Laboratory of High Altitude Medicine, Qinghai, People's Republic of China. \\ ${ }^{3}$ High Altitude Medical Research Center, University of Tibet, Lhasa, People's Republic of China. \\ ${ }^{4}$ Qinghai Cardiovascular Hospital, Xining, People's Republic of China.
}

\begin{abstract}
Accepted 30 May, 2012
High altitude pulmonary edema (HAPE) is the most common of the serious manifestations of altitude sickness, acute respiratory distress syndrome (ARDS) may be secondary to HAPE in some severe cases. The purpose of this study was to evaluate the diagnosis of ARDS at an altitude above $4000 \mathrm{~m}$. Clinical studies were performed in eight patients with ARDS secondary to HAPE at an altitude of $4500 \mathrm{~m}$, 10 patients with pure HAPE occurred at the same altitude were as the control group. All patients were male Han sea-level residents; there was no history of cardiopulmonary disease. After an initial emergency treatment on high mountains, both HAPE and the suspected ARDS patients were rapidly descended to Golmud Hospital at an altitude of $2808 \mathrm{~m}$. The major difference between ARDS and the usual clinical course of HAPE was its severity and prolonged nature. Refractory hypoxemia, higher pulmonary artery pressure, and acute respiratory failure occurred are three features which indicated that ARDS has been secondary to HAPE. In summary, our study showed that diagnosis of ARDS at high altitude (above $4000 \mathrm{~m}$ ) are as follows: 1) Acute onset with 24-48 hr of the predisposing event (HAPE); 2) Chest X-ray shows bilateral infiltrates; 3) No evidence of elevated left atrial pressure, the pulmonary capillary wedge pressure is $\leq 18 \mathrm{mmHg}$; (4) $\mathrm{PaO} 2<60 \mathrm{mmHg}$ with $\mathrm{PaCO}_{2}<50 \mathrm{mmHg}$ indicated a hypoxemic respiratory failure; 5) A ratio of arterial oxygen tension to fraction of inspired oxygen $\left(\mathrm{PaO}_{2} / \mathrm{FIO}_{2}\right)$ of 100 to $150 \mathrm{mmHg}$.
\end{abstract}

Key words: High-altitude pulmonary edema, acute respiratory distress syndrome, diagnosis, the ratio of $\mathrm{PaO} 2$ to the fraction of inspired oxygen $\left(\mathrm{PaO}_{2} / \mathrm{FIO}_{2}\right)$.

\section{INTRODUCTION}

High altitude pulmonary edema (HAPE) is a lifethreatening non-cardiogenic form of pulmonary edema that affects susceptible persons who are rapidly exposed to altitude above $2500 \mathrm{~m}$ (Hackett and Roach, 1990). The acute respiratory distress syndrome (ARDS) is defined by non-cardiogenic pulmonary edema and respiratory failure in the seriously ill patient (Plantadosi and Schwartz, 2004). High altitude hypoxia may be one of the pre-

${ }^{\star}$ Corresponding author: E-mail: wutianyiqh@hotmail.com. Tel: 86-971-6250870. Fax: 86-971-8239212. disposing conditions for the ARDS (Biondi et al., 1986; Laycock and Rajah, 2010).

Clinically, patients with HAPE present dyspnea, bloodstained sputum, and patchy pulmonary infiltrates are much like those seen in ARDS (Houston, 1978). However, a patient with severe HAPE could progress to ARDS as previously reported (Zimmerman and Crapo, 1980). The relationship between HAPE and ARDS is an interesting issue, however, to our knowledge which has not yet been done before.

From 2001 to 2006, a new Qinghai-Tibet railroad linking Beijing with Lhasa was built by more than 100,000 workers, of whom $80 \%$ traveled from their lowland habitat 
to altitude up to $5000 \mathrm{~m}$ to work on the railroad (Wu et al., 2009). The railroad construction provided an opportunity for the investigation and study of acute altitude illness. Reported here are 8 patients with ARDS secondary to HAPE, and how to diagnosis of an ARDS secondary to HAPE in a high altitude field condition was discussed.

\section{MATERIALS AND METHODS}

\section{Study sites and subjects}

The study was performed in two hospitals located near the QinghaiTibet railroad construction sites on mountain Tanggula. One hospital is near the Fenghoushan (mountain Wind-gap) tunnel at an altitude of $4779 \mathrm{~m}$ (PB 417 torr). The second hospital is in the Kekexili area (a sparsely populated zone) at an altitude of $4505 \mathrm{~m}$ (PB 440 torr). The meteorological conditions as provided by the Qinghai-Tibet Weather Bureau during the construction of the railroad were as follows: annual average temperature ranged between 1.0 and $-7.0^{\circ} \mathrm{C}$, average daily sunshine lasted between 7.4 and 8.5 h, relative humidity was between 44 and $58 \%$. From July 1, 2001 to October 31,2005 , a total of 24,703 construction workers worked in the harsh climate, in adverse circumstances and a low-barometricpressure environment (Wu et al., 2009).

All the studied patients were male Han sea-level residents. From sea level, they ascended by train over a period of 3 days first to reach the city of Golmud ( $2808 \mathrm{~m}$ ), which is the starting site of the Qinghai-Tibet railroad. They then reached to the construction sites on mountain Tanggula (at a mean altitude of $4525 \mathrm{~m}$ ) by bus in about $6 \mathrm{~h}$. All patients were first ascent to altitude without previous history of altitude exposure. No patients had a history of cardiopulmonary disease, and none reported taking acetazolamide or dexamethane for prevention and treatment of acute altitude illness before and after ascent to altitude. Before ascent, a routine physical examination completed with measurements of blood pressure (BP), electrocardiograms (ECGs), chest $\mathrm{X}$-ray, $\mathrm{SaO} 2$ and routine blood tests. The results of physical examination suggested that all the studied subjects were healthy without medical preconditions before ascent.

Acute altitude illnesses were very common in the construction workers; the overall incidence of AMS, HAPE, and HACE in the total workers was approximately 45 to $95,0.45$ and $0.24 \%$, respectively. A total of 112 patients with HAPE were rapidly evacuated through ambulances for about $4 \mathrm{~h}$ from mountain Tanggula to the Golmud City Hospital at an altitude of 2808 m. After hospitalization with an effective treatment, most of the patients with HAPE improved gradually, however, eight patients with severe HAPE did not respond to oxygen therapy, and their conditions rapidly worsened even if descent. According to the symptoms, signs, and laboratory studies, we speculated that ARDS secondary to HAPE may have occurred in these patients (Zimmerman and Crapo, 1980). We made a series of studies and rapidly performed effective systemic emergency treatments. Reports on the pulmonary hemo-dynamic data and the laboratory studies of the eight patients with ARDS secondly to HAPE (ARDSS) are presented in this study. The ten pure HAPE patients (PHAPE) as a control group was matched for age, sex and work type with the ARDS group, and the onset of illness was at the same altitudes of the two groups.

\section{Laboratory studies}

\section{Routing hematology}

For the red blood cell count and total leukocyte and classification, an automatic hematological counter was used (Cell-Dyn 3700,
Abbott, Santa Clara, CA).

\section{Arterial blood gas study}

Arterial blood samples were determined in heparinized radial arterial blood with the patients breathing room air, for the measurement of arterial $\mathrm{PO}_{2}\left(\mathrm{PaO}_{2}\right)$, arterial $\mathrm{PCO}^{2}\left(\mathrm{PaCO}_{2}\right)$ levels, and $\mathrm{pH}$ using a blood gas analyzer (Radiometer ABL-30, Denmark). In addition, synchronous determination of femoral arterial blood gases and mixed venous blood gas for estimations of oxygen delivery $\left(\mathrm{DO}_{2}\right)$, oxygen consumption $\left(\mathrm{VO}_{2}\right)$ and oxygen uptake $\left(\mathrm{O}_{2}\right.$ ext). During repeated examination, oxygen inhalation was inter-rupted at least $10 \mathrm{~min}$ for collection of samples of arterial blood. All blood samples were analyzed immediately on site after collection. The altitude measurements were done upon symptoms onset; HAPE or ARDS was diagnosed during treatment and again after recovered.

\section{Right cardiac catheterization}

A thermodilution Swan-Ganz catheter $(\mathrm{AH}-050007 \mathrm{Fr} 110 \mathrm{~cm}$, four cavities, USA) was introduced percutaneously into the pulmonary artery via the right internal jugular vein without premedication. The pulmonary arterial pressures and pulmonary arterial wedge pressure were measured with HP-160A multifunctional monitor to continuous monitoring for $72 \mathrm{~h}$. Cardiac output (CO) and calculated output index $(\mathrm{Cl})$ were measured by the thermodilution method. The pulmonary arterial resistance calculated by dividing the cardiac index into the difference between the mean pulmonary arterial and wedge pressures $(\mathrm{PAR}=(\mathrm{mPAP}-\mathrm{mPAWP}) / \mathrm{Cl}$. During examination, after breathing room air, all of the studied patients were breathing 100 percentage oxygen (fractional concentration of oxygen in the inspired gas $\left[\mathrm{FIO}_{2}\right]$ of 1.0$)$ through a nebulizer and a non- rebreathing reservoir mask (WK-Respironics). Cardiac catheterrizations were performed within $5 \mathrm{~h}$ after the studied patients were hospitalized.

\section{Doppler echocardiography}

The pulmonary hemodynamic and mean pulmonary artery pressure (mPAP) was simultaneously obtained by Doppler echocardiography as described before (Wu et al., 2009). In short, with a 3.5-MHz twodimensional imaging/Doppler transducer (HP-Sonos 1500, PaloAlto, USA) data were obtained from the parasternal short axis or apical position with the subject lying with a slight left oblique rotation. Recordings were stored on S-VHS videotape for post-hoc analysis by two independent cardiologists experienced in echocardiography. mPAP was estimated using the Kitabatake formula (Kitabatake et al., 1983). A mean PAP $\geq 25 \mathrm{mmHg}$ was considered to indicate pulmonary hypertension (Wu et al., 2009).

\section{Diagnosis of HAPE}

Initially, a field diagnosis of HAPE was assessed with the Lake Louise Acute Mountain Sickness Scoring system (LLSS) which proposed the following diagnostic criteria: In the setting of a recent gain in altitude the presence of the following or at least two of the following symptoms: dyspnea at rest, cough, weakness or decreased exercise performance, chest tightness or congestion; plus at least two of the following signs: rales or wheezing in at least one lung field, central cyanosis, tachypnea and tachycardia (Roach et al., 1993). In the local hospitals on mountain Tanggula and in the Golmud Hospital where chest roentgenograms are available for further diagnosed by Chest X-ray, chest roentgenographic infiltrates 
Table 1. Clinical features between patients with pure HAPE and patients with ARDS secondary to HAPE.

\begin{tabular}{lll}
\hline Symptoms and signs & PHAPE $(\mathbf{n}=\mathbf{1 0})$ & ARDSS $(\mathbf{n}=\mathbf{8})$ \\
\hline Age & $28 \pm 4$ & $30 \pm 3$ \\
Onset altitude & $4500 \mathrm{~m}$ & $4500 \mathrm{~m}$ \\
Onset times & $48-96$ & $96-120$ \\
Cough & dry or productive cough & severe productive cough \\
Sputum & frothy white sputum & copious, usually bloody \\
Dyspnea & severe dyspnea at rest & serious severe respiratory distress \\
Cyanosis & significant & obvious \\
Coma & none & 2 cases \\
Resting HR & $102 \pm 12.5$ beats $/$ min & $134 \pm 14.0$ beats $/ \mathrm{min}^{++}$ \\
Resting RR & $23 \pm 4.0$ breaths/min & $42 \pm 5.0$ breaths $/ \mathrm{min}^{++}$ \\
SBP $(\mathrm{mmHg})$ & $136 \pm 18$ & $122 \pm 12$ \\
DBP(mmHg) & $78 \pm 12$ & $64 \pm 8+$ \\
Rales & moist rales & bubbling rales \\
Hemoglobin, $(\mathrm{g} / \mathrm{dll})$ & $14.5 \pm 2.5$ & $13.4 \pm 5.2$ \\
Leukocytes $\left(10^{3} / \mathrm{cu} \mathrm{mm}\right)$ & $11.6 \pm 2.8$ & $13.6 \pm 2.2$ \\
\hline
\end{tabular}

PHAPE: Pure high-altitude pulmonary edema; ARDSS: acute respiratory distress syndrome secondary to HAPE; HR: heart rate; RR: respiratory rate; SBP: systolic blood pressure, MBP, diastolic blood pressure. ARDSS compared with PHAPE: ++ $p<0.001+P<0.01$. All data were collected at rest, breathing room air and before treatment.

consistent with pulmonary edema were observed in all patients, and provided some additional diagnostic values in evaluating severity and ruling out cardiac failure and other pulmonary conditions.

\section{Assessment of ARDS}

The diagnosis of ARDS was based on the American-European Consensus Conference on ARDS issued definitions that have been accepted by many clinicians and researchers (Bernand et al, 1994). The recommendation covers radiographic, gasometric and clinical categories, including $\mathrm{PaO}_{2} / \mathrm{FIO}_{2}$ ratio. An acute lung injury (ALI) is defined by a $\mathrm{PaO}_{2} / \mathrm{FIO}_{2}$ ratio of equal to or less than $300 \mathrm{mmHg}$ and ARDS is defined by a ratio of less than or equal to $200 \mathrm{mmHg}$. However, this criterion of $\mathrm{PaO}_{2} / \mathrm{FIO}_{2}$ ratio has been widely used in patients at sea level but it not suitable as a diagnostic criterion of ARDS at high altitude due to a result of varying $\mathrm{FIO}_{2}$ from changes in elevation (West and Wagner, 1980, Montes et al., 2010); the $\mathrm{PaO}_{2} / \mathrm{FIO}_{2}$ ratio is lower at higher altitude due to the inspired oxygen pressure decreased with increasing altitude (Perez-Padilla $\mathrm{Jr}$, 2004).

In the present study, we used the $\mathrm{PaO} 2 / \mathrm{FIO} 2$ of 100 to150 $\mathrm{mmHg}$ as an index for diagnosis and to determine the severity of ADRS at an altitude of $4000 \mathrm{~m}$ (Zhang et al., 2001; Wu, 2001). Summarily, assessment of ADRS at an altitude of $4000 \mathrm{~m}$ was as follows: ARDS requires all four of the following features in patients who rapidly ascended to high altitude above $4000 \mathrm{~m}:$ 1) Acute onset; 2) chest X-ray showed bilateral diffuse infiltrates of the lungs; 3) no evidence of elevated capillary wedge, pressure is $\leq 18 \mathrm{mmHg}$; 4) A ratio of $\mathrm{PaO}_{2} / \mathrm{FIO}_{2}$ of 100 to $150 \mathrm{mmHg}$.

\section{Statistical analysis}

The data were expressed as the mean $( \pm S D)$ of the group, and were analyzed by the t-test for paired data. A difference with $p<0.05$ was considered significant.

\section{RESULTS}

\section{Clinical findings}

The main clinical features are summarized in Table 1. As compared with patients with PHAPE, patients with ARDSS presented a progressive and serious severe dyspnea, a more obvious cyanosis and the diffuse fine rales over both lung fields, whereas patients with HAPE presented bubbling rales usually heard on one lung field. Tachycardia and low blood pressure were commonly found in ARDSS. In a patient with HAPE who develop severe respiratory distress and that gets rapidly worsened, ARDS was suspected.

\section{Chest roentgenographic findings}

In patients with ADRSS, chest X-ray showed bilateral diffuse infiltrates consistent with pulmonary edema, patchy or confluent, whereas pure HAPE patients usually manifests as central interstitial edema or the characteristic fluffy as having unilateral or bilateral edema.

\section{Hemodynamic findings}

Hemodynamic studies by right heart catheterization (Table 2) demonstrated that the characteristic findings were pulmonary hypertension both in PHAPE and in ADRSS patients. However, the results of this study showed that patients with ARDSS have increased 
Table 2. Pulmonary hemodynamic in patients with pure HAPE and in patients with ARDS secondary to HAPE.

\begin{tabular}{lccc}
\hline \multirow{2}{*}{ Parameters } & \multirow{2}{*}{ PHAPE $(\mathbf{n}=\mathbf{1 0})$} & \multicolumn{2}{c}{ ARDSS $(\mathbf{n}=\mathbf{8})$} \\
\cline { 3 - 4 } & & Before treatment & After treatment \\
\hline RAP $(\mathrm{mmHg})$ & $9.46 \pm 0.85$ & $13.85 \pm 1.15^{++}$ & $6.87 \pm 0.99^{\Delta}$ \\
PAP $(\mathrm{mmHg}) \mathrm{S}$ & $46.4 \pm 5.6$ & $55.08 \pm 6.8^{\star}$ & $35.04 \pm 3.5^{\Delta \Delta}$ \\
D & $21.6 \pm 3.2$ & $28.12 \pm 5.5^{+}$ & $20.02 \pm 4.5^{\Delta}$ \\
M & $35.8 \pm 3.0$ & $41.63 \pm 3.0^{+}$ & $25.50 \pm 2.9^{\Delta \Delta}$ \\
PWP $(\mathrm{mmHg})$ & $6.28 \pm 3.84$ & $14.00 \pm 4.21^{*}$ & $6.88 \pm 2.23^{\Delta}$ \\
PARI (dyn.s.cm & $396 \pm 33.8$ & $496.50 \pm 100.22^{*}$ & $262.65 \pm 17.23^{\Delta \Delta}$ \\
Cl $\left(\mathrm{L} \mathrm{min}^{-1} \mathrm{~m}^{-2}\right)$ & $4.14 \pm 0.34$ & $4.20 \pm 0.38$ & $4.28 \pm 0.42^{\Delta}$ \\
\hline
\end{tabular}

PHAPE: Pure high-altitude pulmonary edema; ARDSS: acute respiratory distress syndrome secondary to HAPE; RAP: right pulmonary artery pressure; PAP: pulmonary arterial pressure; S: systolic; D: diastolic; M: mean, PWP: pulmonary artery wedge pressure, PARI: pulmonary artery resistance index, $\mathrm{Cl}$ : cardiac output index. ARDSS compared with PHAPE: $++p<0.001+P<0.01,{ }^{*} p<0.02$. ADRS before treatment vs. after treatment: $\Delta \Delta P<0.001$, $\Delta \mathrm{P}<0.01$. All comparative data between PHAPE and ADRSS were collected at rest, breathing room air, and before treatment.

pulmonary arterial vasoconstriction to hypoxia when compared with patients who suffered PHAPE. Patients with ARDSS were found to have a greater pulmonary artery pressure than patients with PHAPE at the same altitude. In addition, after treated immediately with 100 percent oxygen, mPAP decreased significantly in patients with PHAPE, whereas MPAP responded less to oxygen therapy even if descent in patients with ARDSS.

Doppler echocardiography was performed at high altitude field and simultaneously examined with right heart catheterization in the hospital. This technique is the principle noninvasive diagnostic test, and the correlation with directly measured pulmonary artery pressure during right-heart catheterization is high $\left(R^{2}=0.90\right)$. While monitoring the pulmonary hemodynamic, it was observed that both in patients with ARDSS and in patients with PHAPE, their mPAP decreased gradually after rapid descent and effective treatment.

\section{Laboratory findings}

An arterial oxygen tension $\left(\mathrm{PaO}_{2}\right)$ lower than $60 \mathrm{mmHg}$ with a lower arterial carbon dioxide tension $\left(\mathrm{PaCO}_{2}\right)(<50$ $\mathrm{mmHg}$ ) indicated it is a type 1 - hypoxemic respiratory failure in our studied ADRS patients (Table 3). As compared with patients with PHAPE, the level of oxygen $\left(\mathrm{PaO}_{2}\right)$ can stay dangerously lower in ARDSS, even if the patient received oxygen inhalation. A-a DO2 was greater in ARDSS, suggesting that pulmonary diffusing capacity decreased significantly. $\mathrm{PaO}_{2} / \mathrm{FIO}_{2}$ ratio in patients with ADRSS was significantly lower and less response to oxygen inhalation. A marked decrease in $\mathrm{DO}_{2}$ and $\mathrm{VO}_{2}$ was also found in ADRSS patients. Both PHAPE and ARDSS show leukocytosis, suggesting that there is an inflammation response.

\section{Treatment and outcome}

Management centers on supportive care and treating the initial cause of HAPE. All the patients with ARDS were rapid descent and need to be in an intensive care unit (ICU). A hyperbaric chamber is available in Golmud Hospital for treating all patients with ARDS because here is still at an altitude of $2808 \mathrm{~m}$, intubation and mechanical ventilation, and use of positive end expiratory pressure (PEEP) were required because of refractory hypoxemia which did not respond to administration of 100 percent oxygen, medications to treat infections, reduce inflammation using antibiotics and dexamethasone etc. As a result, all patients survived and none died, but their conditions improved gradually and completely recovered for about two to three months after their hospitalization. Furthermore, rehabilitation during recovery needs to focus on such patient.

\section{DISCUSSION}

Our pulmonary hemodynamic study confirmed the previous catheterization studies at altitude and indicated that HAPE is a non-cardiogenic form of pulmonary edema associated with high pulmonary artery pressures and normal pulmonary capillary wedge pressures (Hultgren, 1997). Although PWP was not higher than $18 \mathrm{mmHg}$ both in patients with ARDSS and PHAPE, however, the PWP was higher in patients with ARDSS than that in PHAPE. The pulmonary leak index (PLI, $10^{-3} \mathrm{~min}^{-1}$ ) was significantly higher in ARDS than in HAPE (Maggiorini et al., 2001), suggesting that the hypoxic lung injuries are severe in ARDS than that in HAPE. The characteristics of bronchoalveolar lavage fluid (BALF) indicated that both HAPE and ARDS are a high-protein, high-permeability 
Table 3. Blood gas studies in patients with HAPE alone and in patients with ARDS secondary to HAPE.

\begin{tabular}{|c|c|c|c|}
\hline \multirow{2}{*}{ Parameters } & \multirow{2}{*}{ PHAPE $(n=10)$} & \multicolumn{2}{|c|}{ ARDSS $(n=8)$} \\
\hline & & Before treatment & After treatment \\
\hline $\mathrm{PaO}_{2}(\mathrm{mmHg})$ & $52.6 \pm 4.8$ & $49.88 \pm 3.45$ & $70.34 \pm 2.93^{\Delta \Delta}$ \\
\hline $\mathrm{PaCO}_{2}(\mathrm{mmHg})$ & $25.4 \pm 2.31$ & $24.60 \pm 1.05$ & $28.8 \pm 2.54^{\Delta}$ \\
\hline $\mathrm{pH}$ & $7.54 \pm 0.022$ & $7.57 \pm 0.025^{*}$ & $7.43 \pm 0.018^{\Delta \Delta}$ \\
\hline $\mathrm{A}-\mathrm{a} \mathrm{DO}_{2}(\mathrm{mmHg})$ & $7.89 \pm 4.02$ & $11.52 \pm 4.12^{+++}$ & $5.65 \pm 2.45^{\Delta \Delta}$ \\
\hline $\mathrm{PaO} 2 / \mathrm{FIO}_{2}$ & $134.50 \pm 5.24$ & $126.8 \pm 6.65^{++}$ & $201.60 \pm 4.8^{\Delta \Delta}$ \\
\hline $\mathrm{DO}_{2}\left(\mathrm{~L} \min ^{-1} \mathrm{~m}^{-2}\right)$ & $424 \pm 15.20$ & $409.99 \pm 13.11^{*}$ & $460.89 \pm 13.99^{\Delta \Delta}$ \\
\hline $\mathrm{VO}_{2}\left(\mathrm{~L} \mathrm{~min}^{-1} \mathrm{~m}^{-2}\right)$ & $135.34 \pm 11.60$ & $129.87 \pm 5.28^{*}$ & $158.53 \pm 9.20^{\Delta}$ \\
\hline $\mathrm{O}_{2} \operatorname{ext}(\%)$ & $0.19 \pm 0.02$ & $0.18 \pm 0.01$ & $0.20 \pm 0.01^{\Delta}$ \\
\hline
\end{tabular}

$\left[\mathrm{PIO}_{2}\right]$ 1.0: $\mathrm{PaO} 2$ during the breathing of 100 percent oxygen (the fraction of inspired oxygen (1.0 for $100 \%$ oxygen), DO2: oxygen delivery, VO2: oxygen consumption, $\mathrm{O}_{2}$ ext: oxygen uptake, ARDSS compared with PHAPE: $++p<0.001 .+++p<0.005,{ }^{*} p<$ 0.05. ADRS before treatment vs. after treatment: $\Delta \Delta P<0.001, \Delta P<0.05$. All comparative data except $\mathrm{PaO}_{2} / \mathrm{FIO}_{2}$ between PHAPE and ARDSS were collected at rest, breathing room air and before treatment.

type of pulmonary edema (Schoene et al., 1986). Although the concentrations and size ranges of the protein in the HAPE fluid are similar to those found in ARDS, the predominance of alveolar macrophages rather than neutrophils in the BALF is strikingly different from the lavage cellular profile in ARDS (Schoene et al., 1986; Shoen, 1987). Bronchoalveolar lavage fluid collected through the endotracheal tube for the differential diagnosis between HAPE and ADRS is an important laboratory study. However, it is almost impossible for use in a remote mountainous area.

How to diagnosed ARDS secondary to HAPE in the altitude field? Generally, HAPE is usually described as an altitude illness that rapidly responds to rest, administration of oxygen or descent to lower elevation. Hypoxemia that does not respond to oxygen administration is not a common feature of HAPE (Hultgren, 1997). Also, the clinical observation indicated that HAPE resolves rapidly without residual pulmonary dysfunction and allows persons to be active again after recovered. This scenario is distinctly different from the type of pulmonary edema seen in ARDS. Therefore, the diagnosis of ARDS should be suspected when a patient with HAPE do not respond to oxygen therapy even if descent, instead their conditions worsen rapidly. Chest X-ray shows that HAPE usually manifests as central interstitial edema, whereas ARDS represents the most severe form of permeability edema associated with the acute respiratory failure. Confirmation of the diagnosis can often be achieved through the use of either chest X-ray or $\mathrm{SaO}_{2} / \mathrm{FIO}_{2}$ ratio. For diagnosis of ARDS at an altitude field, arterial blood gases should be evaluated in all patients, and chest radiography is essential; usually, both techniques will be necessary. In addition, pulmonary function tests, blood tests and ECGs may be of help to identify the cause of
ARDS. Right-heart catheterization is sometimes useful for a pathophysiological mechanism study (Zimmerman and Crapo, 1980; Maggiorini et al., 2001), but it is almost impossible to perform at an altitude field. Moreover, using an invasive measurement of catheterization for study on hemodynamic may sometimes have some disadvantages, including increased patients risks and discomfort, thereby limiting its use. From our experience, Doppler echocardiography is the principle noninvasive diagnosis test and the technique is very portable, safer and practical; it is especially useful at a high altitude field and thus deserves recommendation.

ARDS is a syndrome that must meet certain criteria to be diagnosed. An index of $\mathrm{PaO}_{2} / \mathrm{FIO}_{2}$ ratio is probably of greater value in the diagnosis and evaluation of severity and determining the effectiveness of therapy of ARDS (Platadosi et al., 2004; Laycock and Rajah, 2010). This study raises the question of using $\mathrm{PaO}_{2} / \mathrm{SaO}_{2}<200$ $\mathrm{mmHg}$ as a key diagnostic criteria of ARDS at sea level. This diagnostic index is not practicable for an altitude diagnosis of ARDS. In patients with ARDS, the primary physiological mechanism of hypoxemia is shunt (Biondi et al., 1986; Platadosi et al., 2004; Laycock and Rajah, 2010). Shunt is more commonly assessed based on a series of oxygenation indices: the ratio of $\mathrm{PaO}_{2}$ to the fraction of inspired oxygen $\left(\mathrm{PaO}_{2} / \mathrm{FIO}_{2}\right)$, the arterialalveolar oxygen tension gradient of the $\mathrm{PaO}_{2}$ (P[Aa]DO $\left.{ }_{2}\right)$, and the ratio of $\left(\mathrm{P}[\mathrm{A}-\mathrm{a}] \mathrm{DO}_{2}\right.$ to $\mathrm{PaO}_{2}$. In the present study, we used the $\mathrm{PaO} 2 / \mathrm{FIO} 2$ ratio as an index of pulmonary shunt, which is commonly used to diagnosis and to determine the severity of ADRS. At a given shunt, the $\mathrm{PaO}_{2} / \mathrm{FIO}_{2}$ ratio is lower at higher altitude due to the inspired oxygen pressure that decreases with increasing altitude (Zhang et al., 2001; Wu, 2001; Perez-Padilla, 2004; Montes et al., 2010). Therefore, when evaluating 
for ARDS based on $\mathrm{PaO}_{2} / \mathrm{FIO}_{2}$ ratio of $<200 \mathrm{mmHg}$, patients residing at high altitude will have less shunt and, presumably, less severe lung injury than patients at sea level (Perez-Padilla, 2004).

To diagnose ARDS at high altitude, it is not suitable to use $\mathrm{PaO}_{2} / \mathrm{FIO}_{2}<200 \mathrm{mmHg}$ as a key diagnostic criteria. This should be taken into consideration when comparing patients from different altitudes. We considered that there are two ways when using $\mathrm{PaO}_{2} / \mathrm{FIO}_{2}$ ratio as for a diagnostic index of ARDS at high altitude: one is using an adjusted formula:

$\mathrm{PaO}_{2} / \mathrm{FIO}_{2}=\mathrm{PaO}_{2} / \mathrm{FIO} \times(\mathrm{PB} / 760)$

Where PB is the barometric pressure of studied site (West and Wagner, 1980). The second way is according to a mathematical model or a regression coefficient to adjust the $\mathrm{PaO}_{2} / \mathrm{FIO}_{2}$ ratio at a given altitude. We used the latter of $\mathrm{PaO}_{2} / \mathrm{FIO}_{2}$ of 100 to $150 \mathrm{mmHg}$ at an altitude of above $4000 \mathrm{~m}$ in the 8 patients (Zhang et al., 2001; Wu, 2001). During an earthquake in Yushu at an altitude of $4000 \mathrm{~m}$, a total of 85 cases of ARDS due to severe injuries were diagnosed using $\mathrm{PaO}_{2} / \mathrm{FIO}_{2}<150 \mathrm{mmHg}$ (Wu et al., 2012), suggesting that it is a easy, accurate and useful marker for diagnosis of ARDS at high altitude. Arterial blood gas test is easily performed even if at a remote mountainous area.

The development of severe, prolonged acute respiratory failure in these eight patients with HAPE suggests that altitude exposure may under some circum-stances contribute to the development of ARDS in some persons (Zimmerman and Crapo, 1980). In fact, ARDS secondary to HAPE is not uncommon; of the 112 patients with HAPE at an al-titude above $4500 \mathrm{~m}$, eight severe cases met the clinical criteria for the diagnosis of ARDS. Previously, it was re-ported that there is a rare instance of progression to ARDS in patients with HAPE (Hackett and Roach, 1990), which may be due to most cases of HAPE occurring in remote areas. It is possible that those persons with more severe pulmonary edema do not respond to oxygen the-rapy or descent, and therefore die rapidly (Zimmerman and Crapo, 1980). Moreover, ARDS as the end stage of HAPE process, can lead to multiple organ failure (Platadosi et al., 2004; Laycock and Rajah, 2010), hence we should be highly suspicious of this condition followed by insistence on immediate descent since, as in these patients medical treatment is so ineffective, with a fatal outcome. Meanwhile, an early diagnosis is a key factor of an early effective treatment.

\section{ACKNOWLEDGEMENTS}

This study was supported by the "973" National Key Basic Research and Development Program (No, 2012CB518202) and Project of Qinghai Development of Science and Technology (No. 2011-N-150).

\section{ABBREVIATIONS}

AMS, Acute mountain sickness; HAPE, high altitude pulmonary edema; HACE, high altitude cerebral edema; ARDS, acute respiratory distress syndrome; ALI, acute lung injury; BP, blood pressure; ECG, electrocardiography; $\mathrm{SaO}_{2}$, arterial oxygen saturation; PB, barometric pressure; $\mathbf{P a O}_{2}$, partial pressure of oxygen in arterial blood; $\mathbf{P a C O}_{2}$, partial pressure of carbon dioxide in arterial blood; $\mathbf{A - a} \mathbf{D O}_{2}$ : the differences between $\mathrm{PAO}_{2}$ and $\mathrm{PaO}_{2}\left(\mathrm{PAO}_{2}-\mathrm{PaO}_{2}\right) ; \mathrm{FIO}_{2}$, the fraction of inspired oxygen; mPAP, mean pulmonary artery pressure; PAR, pulmonary artery resistance; PEEP, positive end expiratory pressure.

\section{REFERENCES}

Bernand GR, Artigas A, Brigham KL, Carlet J, Falke K, Hudson L (1994). The American-European Consensus Conference on ARDS. Definitions, mechanisms, relevant outcomes and clinical trail coordination. Am. J. Respir. Crit. Care Med. 149(3/l):818-824.

Biondi JW, Hines RL, Barash PG, Baker CC, Matthay MA, and Matthay RA (1986). The adult respiratory distress syndrome. Yale J. Biol. Med. 59(4):575-597.

Hackett PH, Roach RC (1990). High altitude pulmonary edema. J. Wild Med. 1(1):3-26.

Houston CS (1978). Lessons from high altitude pulmonary edema. Chest 74(4):359-360.

Hultgren HN (1997). High altitude pulmonary edema. In: Hultgren HN (ed). High Altitude Medicine. Hultgren Publications, Stanford, California pp. 256-315.

Kitabatake A, Inoue M, Asao M, Masuyama T, Tanouchi J, Morita T (1983). Noninvasive evaluation of pulmonary hypertension by a pulsed Doppler technique. Circulation 68(2):302-309.

Laycock $H$, Rajah A (2010). Acute lung injury and acute respiratory distress syndrome: A review article. BJMP 3(2):324-332.

Maggiorini M, Melot C, Pierre S, Pfeiffer F, Greve I, Sartori C, Lepori M, Hauser M, Scherrer U, Naeije R. (2001). High-altitude pulmonary edema is initially caused by an increase in capillary pressure. Circulation 103(16):2078-2083.

Montes MM, Padua MA, Guzman CIO, Granillo JF (2010). Ajuste de la relacion $\mathrm{PaO}_{2} / \mathrm{FIO}^{2}$ a la presion barometrica: Presion barometrica$\mathrm{PaO}_{2} / \mathrm{FIO}_{2}$. Rev. Asoc. Mex. Med. Crit. y Ter. Int. 24(1):8-12

Perez-Padilla JR (2004). Altitude, the ratio of $\mathrm{PaO}_{2}$ to fraction of inspired oxygen, and shunt: impact on the assessment of acute lung injury. Arch. de Bronconeumonogia 40(10):459-462.

Plantadosi CA, Schwartz DA (2004). The acute respiratory distress syndrome. Ann. Intern. Med. 141(6):460-470.

Roach RC, Bärtsch P, Oelz O, Hackett PH (1993). The Lake Louise acute mountain sickness scoring system. In: JR Sutton, CS Houston, G Coates (eds). Hypoxia and Molecular Medicine. Queen City Press, Burlington, VT, USA. pp. 272-274.

Schoene RB, Hackett H, Henderson R, Sage H, Chow M, Roach RC, Mills WJ, Martin TR (1986). High altitude pulmonary edema: Characteristics of lung lavage fluid. JAMA 256(1):63-69.

Schoene RB (1987). High-altitude pulmonary edema: pathophysiology and clinical review. Ann. Emerg. Med. 16(9):987-992.

West JB, Wagner PD (1980). Predicted gas exchange on the summit of Mount Everest. Resp. Physiol. 42(1):1-16.

Wu TY (2001). High altitude pulmonary edema and adult respiratory distress syndrome. J. High Alt. Med. 11(2):63-66.

Wu TY, Ding SQ, Liu JL, Yu MT, Jia JH, Duan JQ, Chai ZC, Dai RC, Zhang SL, Liang BZ, Zhao JZ, Qi DT, Sun YF, Kayser B (2009). Reduced incidence and severity of acute mountain sickness in Qinghai-Tibet railroad construction workers after repeated 7-month exposures despite 5-month low altitude periods. High Alt. Med. Biol. 10(3):221-232. 
Wu TY, Li SZ, Hou SK, Loubu O (2012). A successful mountain rescue operation in Yushu earthquake. Eng. Sci. 10(1):2-7.

Zhang SF, Liu SX, Gao W, Liu HP, Liu Y, Zhang DH (2001). Report of the consensus conference on diagnostic criteria of ALI/ARDS at high altitude in Western China. Intensive Care Med. 27(3):1539-1546.
Zimmerman GA, Crapo RO (1980). Adult respiratory distress syndrome secondary to high altitude pulmonary edema. West J. Med. 133(4): 